\title{
INTEGRATING HUMAN RESOURCE DEVELOPMENT AND KNOWLEDGE MANAGEMENT FOR SUSTAINABLE BOTSWANA PUBLIC SECTOR PERFORMANCE
}

\author{
Theophilus TSHUKUDU
}

\begin{abstract}
Human resource development and knowledge management are increasingly becoming influential disciplines which are critical to the survival and success of organizations. Human capital resources are key for organizations to gain competitive advantage. With the spread of information and worldwide communications, competitive advantage based on only technology and on only human resources development strategies may only be maintained for short periods of time before competitors catch up. The only source of sustainable competitive advantage is to learn faster and more creatively than competing organizations. That could only be achieved through the swift and effective HRD strategies combined with knowledge management. It has been established that through learning, training, development, knowledge and knowledge management can organizations thrive through human capital. Helping people grow by empowering them with knowledge in a way boosts performance in a sustainable way. To memorize information for extended periods of time is not practical, it is telling that information needs to be stored (managed properly) for reference and for sustainability.

Keywords: Knowledge Management; Human Resource Development; Sustainability; Human Resource Management; Organization
\end{abstract}

DOI: 53373/ REDS.2021.53.4.044

\section{INTRODUCTION}

A vast array of literature has demonstrated how knowledge management (KM) has an integrated impact on the three perspectives of sustainability: Economic, environmental, and social. KM has positioned itself as one of the major critical success factors for the competitiveness of large firms, small and medium enterprises (SMEs), and startups. In recent years, an increasing number of contributions are showing how firms can leverage KM in promoting significant innovations and cultural changes that leverage organizational sustainability across business and environmental and social justice contexts. On the other hand, knowledge sharing processes within firms and other stakeholders allow firms to achieve sustainable environmental, financial, and social goals. Subsequently, managing the impact of industrial firms' operations on the environment could be supported by the adoption of innovative knowledge management systems (KMSs), namely the integration of knowledge management tools and practices. (Anand, Centobelli, Cerchione, \& Lindahl, 2020). Nowadays enterprises have been extremely efficient in collecting,

* Department of Management, Faculty of Business, University of Botswana. 
organizing, and storing a large amount of data obtained in their daily operations. Most of these enterprises, however, do not use such data properly so as to transform them into knowledge to be employed in their own activities.

Human Resource Development (HRD) is a newly emerging study in the field of management. This newly emerging study in the field of management is fast driving out the traditional term personnel management' and substituting a new term 'human resource development'. Though development of human beings has been in existence in one form or another since time immemorial, a systematic and planned approach to HRD in the company form of organization emerged in the latter half of the 20th century (Ragini, 2019). The most important aspect of HRD is to retain the knowledge invested over time on individuals. Employment has become more mobile, where individuals change their jobs in pursue of building their career. In other words, as an individual leaves an organization, the knowledge also leaves with him. Finding ways to retain this knowledge in a database or in retrievable form that is accessible by others in the organization turns information into useful knowledge crucial to improve process and increase profits (Bogardus, 2004). For example, Corus's information sharing network is backed up by databases that are shared by firms all over the world. A problem in a firm operating in Canada can get the solution and best practices that was applied for the similar problem in a firm operating in another country.

Human Resource Development (HRD) is a relatively new discipline which has yet to be clearly defined and is often confused with Human Resource Management (HRM) but it is worth noting that the two although similar, they are distinct notions. Human resources management is related to the management and maintaining of the employees in the organization whereas Human resource development concept is more into the development part for the employees and the organization both. With the lack of a clear consensus on the exact definition of HRD, this has not dissuade certain scholars from attempting to define it.

Human resource development Management identifies, nurtures and uses the abilities of the employees working for the company. They are there to create a suitable climate for their people to help them and the companies develop. It creates a structure for helping the employees of the organization in developing their organizational and personal abilities, know-how and skills. HRD is a continuous and planned manner in which the employees of an organization are guided to perceive the following points;

- To gain and polish their abilities that are required to execute different roles which are related to their existing and future job responsibilities to help them perform well.

- Human resource development helps the employees develop their inner potential and also learn new ones by learning how to explore their own capabilities for self as well as organizational development.

- It also develops the organizational culture in which the relationship between the supervisor and the subordinate contributes to collaborate amongst different units 
in the organization with teamwork and strong contribution of professional well-being by motivating the pride of the employees.

World Development Report of 1999 denoted that for many countries, the degree of knowledge application is becoming a key measure of human capital and industry. Today's technologically advanced economies are setting great examples of typical knowledge-based economies. Contemporary organizations are currently going through the turbulent storm of change and uncertainty occasioned by fast paced technology, intense competition, globalization, changing government regulations, changing demographics and customer expectations and demands, etc. In order to keep up with the prevailing state of flux, actions must be proactive, adaptive, creative, innovative and responsive. Organizational capability depends on human resource capability which is a factor of human resource development. A firm's competitive advantage "can be achieved by recruiting and maintaining a well-trained labor force and managers whose knowledge, skills and abilities serve as a source of innovation (Zahra and Nielsen, 2002). (Akinyemi, 2011)

For centuries, scientists, philosophers and intelligent laymen have been concerned about creating, acquiring, and communicating knowledge and improving the re-utilization of knowledge. However, it is only in the last few decades that a distinct field called "knowledge management" (KM) has emerged. KM is based on the premise that, just as human beings are unable to draw on the full potential of their brains, organizations are generally not able to fully utilize the knowledge that they possess. Through KM, organizations seek to acquire or create potentially useful knowledge and to make it available to those who can use it at a time and place that is appropriate for them to achieve maximum effective usage in order to positively influence organizational performance. It is generally believed that if an organization can increase its effective knowledge utilization by only a small percentage, great benefits will result (Levitt and March, 1988, p. 319)

\section{PROBLEM STATEMENT}

We do seem to acknowledge and agree that organizations need to be adaptable, humanistic, and ethical. Leadership should be transformational, yet situational. Structure and work processes should be designed to meet both employees' and customers' needs. Organizations should be sustainable and socially responsible (Morris 2014). A number of researchers have carried out studies attempting to demonstrate a link between Human Resources Development and performance. While Purcell et al (2003) commented that when successful firms invest in HRM practices they may do so to help sustain high performance, Wood (1999) on the other hand, had previously captured that the quality of the research base supporting the relationship between HRM and performance is weak. Little work has been done to explore the relevance. 
In the same breadth, there is an idea amongst scholars that strategic knowledge is increasingly becoming an engine for change and creativity in many industries and organizations: enabling effective operational and strategic initiatives. Existing literature in knowledge management (KM), however, has focused mainly on generic outputs obtainable from KM systems. These two paradigms seem to be vital to the success of any organization. To the naked eye it seems like human resources development and knowledge management separately are vital to the success of the firm/ business/organization. One may be tempted to think that they could be paired together for the good of the business. Again, from the studied literatures, it is evident that there are misgivings regarding their contribution to the business performance and its sustainability. This disapproval requires solutions. One of the most progressive solution may come in the form of integrating human resource management practices, specifically HRD with knowledge management to enhance and sustain organizational performance. This qualitative study will examine the role that human resources development and knowledge management combined can play in the business performance from the sustainability point of view. The study will review literatures from previous researchers who researched on topics related organizational performance, HRD and KM's contributions to the organizational performance and those that attempts to assimilate HRD and KM. Although literature exists between HRM, HRD, KM and Sustainable Performance it is inadequate and ambiguous at best as most researchers have not definitively conceptualized links between HRD, KM and Sustainability.

\section{AIM OF THE STUDY}

The study generally aims at assessing the relationship between human resource development and knowledge management for the sustainable performance of the business/ organization.

Specifically, the study aims to fulfil the following objectives;

- To identify the role played by the implementation of knowledge management in a business

- To identify the role played by HRD on the performance of the firm

- To assess the plausible possibilities of having an integrated human resource development and knowledge management working together to achieve the set out organizational goals as well as sustainability.

To achieve this, a detailed literature review on the implications of KM on effective human resource development, is presented. Further, the consequences for an organization's ability to sustain competitive position in the marketplace is discussed. 


\section{SIGNIFICANCE OF THE STUDY}

The study of the integration of HRD and KM can be a learning paradigm in all the organizations to enhance knowledge through institutional memory and documentation for the benefit of future generations the resultant of which could be to pride self with knowledgeable human resource that could contribute to the growth of the organization. A knowledgeable workforce will display a spectacle performance that would ensure the business achieves its corporate goals, and maximize profits to achieve sustainability. There is a multitude of human resource practices that have been shown to have a positive correlation with business performance (Kesti,2012) and this one aspect, too needs to be tested if it is a significant contributor.

\section{LITTERATURE REVIEW}

\section{Introduction. Definitions. Human Resource Development (HRD)}

Several definitions have been provided for human resource development (HRD) during the past few decades (Gilley \& Eggland, 1989; Lee, 2003; McCracken \& Wallace, 2000; McLean \& McLean, 2001; Nadler, 1983; Nadler \& Wiggs, 1986; Smith, 1988; Swanson, 1995). There are three areas of professional practice including learning, performance, and change that are generally identified in the definitions of HRD. For example, Swanson (1995) defined HRD as "a process of developing and unleashing human expertise through organization development and personal training and development for the purpose of improving performance" ( $p$. 207). Nadler (1983) defined HRD as "organized learning experiences in a given period of time to bring about the possibility of performance change or general growth for the individual and the organization" (p. 1). McLean and McLean (2001) described HRD in a global perspective: Human resource development is any process or activity that, either initially or over the long term, has the potential to develop work-based knowledge, expertise, productivity and satisfaction, whether for personal or group/team gain, or for the benefit of an organization, community, nation or, ultimately, the whole of humanity. (p. 322). Most definitions include, at minimum, the need for organizational efforts to result in performance improvement and organization development that enhance the organization's competitiveness and effectiveness. Swanson and Arnold (1996) elucidates that HRD is a sub-system that operates in the main system; the organization. In order for the organization to be successful the objectives and goals of the subsystems must be aligned towards achieving the set goals of the main system. For example, the primary objective of the organization would be to maximize return on shareholder investment. We may find that the objectives of training and development would be a level removed down, that is to maximize the capabilities of the employees, induce innovation, and produce 
high quality products and service. They may be different but a closer look at each of these objectives reveals that they serve a singular purpose; maximize the return (Swanson \& Arnold, 1996, p.15).

\section{Knowledge}

Knowledge is defined as the ability to sustain the coordinated deployment of assets and capabilities in a way that helps the firm achieve its goals (Fawzy \& Soliman, 2000). These assets, or "Knowledge Treasures", need a knowledge map which describes how to find, what to find and where to find useful knowledge within the organization. Acquisition and enhancement of these assets have become crucial management concerns (Al-Atahari and Zairi, 2001). In the new economy of the new millennium, knowledge has emerged as an asset to be valued, developed and managed. It is a critical factor affecting an organization's ability to remain competitive in the new global marketplace. Some argue it has supplanted the traditional factors of production - land, labor and capital - to become the preeminent corporate and competitive resource (Maureen and Elaine, 2002). This is because knowledge does not wear out and people can duplicate it practically without cost. It is a source of value and productivity, where knowledge can add value to an otherwise closed, zero-sum system of value, and it can increase value without diminishing it somewhere else.

Knowledge or "intellectual capital", could be in three forms, namely: Human capital (evidenced in staff's knowledge, skills and talents); Structural capital (comprised of systems for codifying, storing, transmitting and sharing knowledge); and Customer capital (resulting from connections between organizations and clients, vendors and partners) (Fawzy and Soliman, 2000). More recently, Audrey and Smith (2001) define knowledge as understanding, awareness, familiarity acquired through study, investigation, observation, or experience over the course of time. It is an individual's interpretation of information based on personal experiences, skills, and competencies.

To the organization, knowledge is defined as what people know about customers, products, processes, mistakes and success (Audrey and Smith, 2001). They further add that such knowledge resides in databases or through sharing of experiences and best practices, or through other sources both internal and external to the organization. Knowledge can be explicit, cognitive or tacit.

\section{Knowledge Management}

The term Knowledge Management (KM) is used to refer generally to all efforts to enhance and increase the value of the generation, sharing and application of knowledge (Dawson, 2000). The complexity behind the definition of KM is partially due to the difficulties in identifying knowledge itself. Many varying definitions of $\mathrm{KM}$ appear in literatures. One of the well-known definitions is provided by Davenpor and Prusak (1998): KM is concerned with the exploitation and development of the knowledge assets of an organization with a view to furthering the organization's objectives. The knowledge to be managed includes both explicit, documented knowledge, and tacit, subjective knowledge. The scope of knowledge management 
is wide and the existing literature gives an endless number of definitions for knowledge management. The definitions and activities involved depend largely on which they are intended for, and every firm has different approach to their knowledge management practices, it is concerned with capturing a firm's stock of expertise through creation, collection, storage and application (Bollinger and Smith, 2001). It means identifying and harnessing the collective knowledge of the organization gained through experience and competencies.

Organizations are interested in managing knowledge for several reasons; One reason is that core competencies are based on the skills and experience of the people who do the work and may not exist in the physical form (Kridad and Goulding, 2006). Therefore, it is important that firms find ways to tap into this knowledge base in order to preserve and expand their core competencies (Bollinger and Smith, 2001). In view of this, knowledge management has become a critical subject of discussion in the business literature in the recent years. Both business and academic communities believe that, by leveraging knowledge, a firm can sustain its long-term competitive advantage. Knowledge management ideally captures, transfers, and leverages what everyone in the firm knows. Thus, there is a daunting challenge as who is 'everyone in the organization' and how does the firm manage its knowledge, human capital, thus transforming it into intellectual capital.

\section{Sustainable performance}

The concept of performance covers both what has been achieved and how it has been achieved. The most obvious way to measure what has been achieved is by reference to key performance indicators, which are usually to do with financial results (profitability) or assessments of organizational capability or effectiveness. The how part is more difficult, it has to rely on qualitative assessments of organizational capability of effectiveness.

Sustainable performance can, therefore be defined as the adoption of performance strategies and practices that enable the achievement of financial, social and ecological goals, with an impact inside and outside of the organization and over a long-term time horizon while controlling for unintended side effects and negative feedback.

While it can be argued that there is a reasonable consensus on the nature and scope of HRM, its components and principles, this is not the case where KM is concerned. Accordingly, before one can undertake an analysis of the relationship between the two areas, it is necessary to state as clearly as possible what is understood by $\mathrm{KM}$ and what is HRD. This has been fully discussed at the background section.

\section{Knowledge management}

Knowledge management is introduced. Much of the literature of KM continues to reflect a techno-centric focus, similar to that of information management, which in essence regards knowledge as an entity that can be captured, manipulated and leveraged. This is a limited and ultimately hazardous perception. Critical to any realistic understanding of knowledge and its incorporation into the management of 
organizations is awareness of a range of views on the concept, which includes perceptions of knowledge as an entity (akin to information), as a resource, as a capacity and as a process. For present purposes, it is important that knowledge is viewed as a social creation emerging at the interface between people and information and especially within communities engaged in communication, knowledge-creation and knowledge sharing and learning. According to Rumizen (2002) from an operational perspective, KM can be described as the systematic processes by which an organization identifies, creates, captures, acquires, shares and leverages knowledge. (Gloet, 2006).It is suggested there are two main models, the dominant technology-focused one and a people-oriented one. Neither model recognizes that HRD might play a role in knowledge management; HRD writers have also ignored knowledge management. Knowledge management rests implicitly on a definition of 'knowledge'. Three perspectives on knowledge are outlined, and it is argued that, however knowledge is defined, HRD skills and knowledge will be essential to managing it. The emerging situative perspective provides the strongest theoretical basis for knowledge management's need for HRD. (Gourlay, 2010)

For instance, while knowledge in itself may be difficult to manage, all the related technologies, structures, instruments, stocks, flows and even people are susceptible to a range of management disciplines and activities, including accountability and control. Given that these activities largely concern intangibles, it is important to think of management in a post-industrial context, with implications for organizational structures, resources, cultures and strategies, management styles and the roles and expertise of staff. When this is coupled with a focus on sustainability, the level of complexity only increases. (Gloet, 2006)

Ahmad et al. (2017) add that knowledge management is a topic around the increase in strength of an organization to benefit it from correct methods of information management and organizational acquisition, which can influence operative performance, business, and organization. Focusing on innovation activities, we can expect the business to grow and flourish such that the business becomes hopeful of its survival by improving performance. Shujahat et al. (2019) believes that knowledge-based employees can boost the relationship and the impact between knowledge management and innovation. In the following, each studied variable is presented.

\section{Knowledge Management Practices}

Knowledge management practices result in the supply of competencies and required capacities to empower the organization (value creation) through knowledge discovery and novel methods. Knowledge management functions develop innovation capacities and functional outcomes. Applying knowledge management practices like creating and sharing knowledge leads organizations to growth, innovation, the creation of new business models, and the creation of proper position in their own industry. It can be stated that, with creation and expansion of knowledge networks, not only organizations benefit, but it can be beneficial for the society, 
environment, and economy. By developing knowledge activities, an organization designs a proper strategy to interact with the environment, which create a sustainable competitive advantage by leading these activities. The vastness of knowledge management practices is of high importance, to the extent that it fertilizes general and technical capacities in the organization along with the impact on innovation practices within the organization. Knowledge management increases the formality of accessing experience, knowledge, expertise, and new abilities and increases the value transferred to customers by encouraging innovation procedures. The results obtained from this procedure, improves knowledge and experience in organization along with improvement of innovation. Knowledge management practices in this research are considered through four aspects (knowledge creation, knowledge acquisition, knowledge storage, and knowledge sharing)

\section{Sustainable Balanced Performance}

In order to create a comprehensive mechanism for success against economic dangers and confronting environmental, economic, and social problems, organizations need comprehensive approaches to overcome threats, obtain success, and react properly to responsibilities in society and the environment. The origin of these approaches and tools considering sustainable balanced performance and sustainable-oriented management can be traced in the concepts presented by Kaplan and Norton (2011). Sustainable balanced performance can be sought in the goals of integration and organizational strategies with social, ethnical, and environmental goals. (Valmohammadi, Sofiyabadi, \& Kolahi, 2019)

\section{Strategic knowledge}

Strategic knowledge is increasingly becoming an engine for change and creativity in many industries and organizations: enabling effective operational and strategic initiatives. By adapting current dynamisms in knowledge management and innovation practices, organizations can expect proper results and improved performance. For instance, when a company wants to grow in new emerging markets like Vietnam and Indonesia rather than India or Brazil then most important task is to transfer the knowledge and working culture.

\section{Human resource development}

Human Resource Management (HRD) strategies develop the conditions to achieve strategic goals and objectives of the organizations by influencing employee behavior. Bowen and Ostroff (2004), differentiate the features of the HRM system that will contribute the organizational performance. Process refers to the design of the HRM system that allows employees to create desired response. Delery and Doty (1996), differentiate three modes of theories in strategic HRM.

These modes are universalistic, the contingent and the configurationally. Universalistic mode linked to best HRM policies and high-performance work strategies. There is a linear relationship between HRM strategies and performance 
of the organization. The best HRM strategies can be successful and applied universally in all type of organizations. The best way to measure the performance of the organization is the measure of profit, sales and its shares in the market. Pfeiffer (1994), argued that to achieve high profit and productivity, the strategies of HRM like training (HRD component), incentive pay, job security, promotion and skill development (another HRD component) will be used. (Unknown, 2018)

In terms of the HRM function, the rise of the so-called knowledge economy has had a major impact, with a considerable shift from HRM as a bureaucratic "personnel management" operation to the development of discrete HRM functions over the past few decades. This has been accompanied by the integration of these functions to support competitive advantage and a more strategic thrust. Having said this, a considerable number of experts in the area warn that HRM faces extinction if it does not respond to changes brought about by the shift from a traditional to a knowledgebased economy (Lengnick-Hall and Lengnick-Hall, 2003; Saint-Onge, 2001; Stewart, 1997; Ulrich, 1997; 1999). Unable to add value under these conditions, the HRM function is perceived to be under extreme threat (Stewart, 1997; Stone, 2002). It has been suggested that one way for HRM to reinvent itself is through its contribution to effective linkages between human capital management and KM within organizations (Fitz-enz in Chatzkel, 2002; Gloet, 2004; Saint-Onge, 2001). The problems in emerging market are find new talent and develop new talent. Generally, company adopts method of sending business leader from eastern developed market to new developing country and train local talent. Also, some companies do reverse things as well. (Mali, 2013).

Western Europe, North America and most of the developed countries are trying their best to get out of the economic slowdown. There are many problems due to the changes in the economic, political, and technical environments. Talent shortage is one of the biggest problems for big companies. Google is managing to attract new talent and retain their workers due to their innovative and flexible HR practices (Talent Search, 2010). Business plan should recognize at first that human resource management as an integral part of the business strategies. To compete in the highly changing environment, companies need to come out with new innovative products in market. But for the innovation it is necessary that talented and experienced employees should be there with the company for long enough time to develop such products. HR helps to hire and train new talent and develop innovative approach. The most important thing is to keep "star" or "A list" managers with company for long time. These human capitals are irreplaceable so need to handle them in accordance with their expectation. (Mali, 2013)

The rapid growth of technology has led to an economy where competitive advantage is increasingly based on the successful application of knowledge (Lengnick-Hall and Lengnick-Hall, 2003). Knowledge, with its intangible aspects, is becoming a defining characteristic of economic activities, as opposed to tangibles such as goods, services or production processes.A revitalization of the HRM function to respond to the demands of the knowledge economy and to develop linkages with 
KM requires major changes across four key areas: Roles, Responsibilities, Strategic focus and Learning focus.

\section{Roles}

Lengnick-Hall and Lengnick-Hall (2003) take the view that in the knowledge economy, organizations will need HRM that is characterized by a new set of roles that can assist in generating and sustaining organizational capabilities. These new HRM roles are those of human capital steward, knowledge facilitator, relationship builder and rapid deployment specialist. The human capital steward recognizes the value of intellectual capital, must ensure that human capital is available, effective and that it will grow in value; this means brokering the services of knowledge workers. The knowledge facilitator places emphasis on learning and development, the effective management of knowledge and creating environments conducive to knowledge creation, sharing and dissemination. The relationship builder focuses on creating and sustaining networks and communities of practice, of joining together people in various parts of the supply chain in new ways. The rapid deployment specialist faces the challenge of rapidly changing markets where information, business processes and organizational design can be combined in different ways to meet ever changing dynamic environments characteristic of life in the knowledge economy. KM has the capacity to significantly broaden the role of the HRM professional.

\section{Relationships}

HRM in the knowledge economy should reflect a responsibility for developing and sustaining organizational capabilities through activities that overlap with traditional business functions such as strategy formulation and implementation, finance and marketing, as well as new functions such as KM. This requires developing new relationships that reflect a shared responsibility among managers, employees, customers and suppliers for HRM (Lengnick-Hall and Lengnick-Hall, 2003; Saint-Onge, 2001; Soliman and Spooner, 2000; Ulrich and Smallwood, 2003; Yahya and Goh, 2002). KM can create a new role for HRM that can provide the means by which to forge new relationships.

\section{Strategic focus}

In the knowledge economy a primary focus of HRM should be the development of human capital and the management of knowledge. MacDonald (2003) identifies a need for HR professionals to identify and channel intellectual capital towards the development of a concise set of core competencies, strengths and capabilities. An emphasis on traditional long term strategic development and long range planning in HRM need to be complemented by a more short term strategic approach that can be responsive to unpredictable, dynamic, fluid environments which characterize the contemporary business world. In conjunction with a short-term strategic focus, organizations need to be thinking about long-term sustainability as well as constant 
renewal and revitalization. As Lengnick-Hall and Lengnick-Hall (2003) suggest, a rapid deployment specialist can respond to the need for business processes and teams that can be rapidly mounted and then reconfigured to suit the changing needs of business environments characteristic of the knowledge economy.

In order to gain competitive advantage from KM, organizations need to identify core competencies, or integrated knowledge sets, that distinguish them from competitors and add value for customers (Bohlander et al., 2001). Ulrich (1997; 1999) refers to these knowledge sets as organizational capabilities and suggests that HRM can play an important role in creating and developing the organizational capabilities required to compete in the knowledge economy. Saint-Onge (2001) also alludes to the need for the HR function to transform itself in order to respond to changing requirements of the knowledge era. He suggests that a strategic capabilities approach where resources are structured across individual capabilities, organizational capabilities and knowledge architecture. The role of the HRM professional will then focus on integrating individual, team and organizational learning for the benefit of both customers and shareholders. HRM can play an important role in creating and developing the organizational capabilities that form part of contemporary KM strategies geared to creating wealth from intellectual capital while maintaining a commitment to sustainability imperatives.

\section{Learning}

A pivotal aspect of life in the knowledge economy is the need for learning. The emphasis on discrete HRM practices is broadening to a focus on developing themes and creating environments conducive to learning, as well as to the acquisition, sharing and dissemination of knowledge within organizations. This includes creating and sustaining learning environments and nurturing communities of practice. The new role for HRM includes managing intellectual capital and developing human capital within the organization. There is the need for a strong emphasis on constant renewal, or revitalization of the organization. Fitz-enz (in Chatzkel, 2002) views human capital as the only active asset within the organization. In referring to the four human capital domains of acquiring, maintaining, developing and retaining, Fitz-enz views the development aspect as unique in the sense that only people can be developed. The development domain holds the key to achieving organizational change, growing individual and team capabilities and creating value while simultaneously attending to sustainability imperatives.

Soliman and Spooner (2000) view employees' collective knowledge as competitive advantage and suggest that the HRM function is well positioned to ensure the success of KM programs which are directed at capturing, using and reusing employees' knowledge. Moreover, HRM can assist in employee development, building quality, creativity, leadership and problem-solving skills (Yahya and Goh, 2002). HRM can also make a significant contribution by developing expertise in how to manage learning, re-using knowledge through lessons learned and surfacing knowledge, know-how and best practice behaviors (Martin, 2000). Lengnick-Hall 
and Lengnick-Hall (2003) also see HRD as pivotal in developing and sustaining a learning focus through facilitating continuous learning, identifying sources of employee knowledge, understanding the mediators that facilitate knowledge sharing and making information available to employees. (Gloet, 2006).

\section{FINDINGS}

From the review above, the key findings emerge:

- Learning can bestow a technical advantage.

- Workers can contribute more effectively when they understand how their work fits with the organizational strategy

- HRD practices can make substantial impact on firm performance

- HRD helps to adapt changes through the development of existing human resources in terms of knowledge and skill

- The study highlights that little is known about putting HRD \& $\mathrm{KM}$ in one basket to ensure sustenance.

\section{DISCUSSION}

\section{Comparisons}

By organizing, integrating, and evaluating previously published material identified in a comprehensive literature review, this research identified the relationship between strategic HRD practices and organizational learning. There are many arguments in the literature stressing that knowledge is the subject for companies to focus on because of the increasing competitive market place. For instance, in classical economies, the sources of wealth are land, labor and capital (Civi, 2000). However, in this 21 st century, other engines of wealth are at work. It takes many forms: technology, innovation, science, expertise, creativity and information. In a word, it is knowledge.

Thus, knowledge is certainly the best resource and the only sustainable competitive advantage. In a growing number of countries, with expanding firms contributing, this knowledge is migratory in some forms, embedded, and slow to be retrieved in other forms (Civi, 2000). Building on this, Nonaka (1995) pointed out that successful companies are those that consistently create new knowledge, disseminate it widely throughout the firm and quickly embody it in new technologies and products: explicit and tacit (McCampbell, Clare \& Glitters, 1999).

\section{Casual arguments}

The study has proved that both HRD \& KM are vital to the success and the sustainability of organizations. The world is a global village, as it has been proven by the internet (social media, IOT, 4IR), organizations thrive through knowledge. 
And it is only through storage and maintenance (knowledge management) that the world can know about you and be able to dig archives when knowledge is managed. Knowledge can be transferred only when it is properly managed. It is only thorough recruiting knowledgeable and trainable workforce that you can achieve sustenance. And having HR as a partner would make or break the organization. From the literature review it is also evident that many see $\mathrm{KM}$ as playing information system role. One of the key functions of KM ia that of referencing tool. It is also worth noting that the benefits of KM are endless. Not only the business benefits from KM, but the society in general. Relationships are built through interactions and that is how sustainability is built

\section{Speculations}

An acknowledgement of a considerable discussions among researchers as to why they think HRD should integrate with KM is however noted, that HRD may face distinction if it does not integrate with $\mathrm{KM}$. The author speculates that this might be because $\mathrm{KM}$ is technological based, while HRD is manual.

\section{Deductive}

One can deduct from the literature that the human resources and knowledge management practitioners don't necessarily have a valid reason as to why they can be woven together to become one. One can deduct from the reviews that neither wants to be swallowed by the other.it may seem like it is all about perceptions and power.

\section{Limitations}

While there is no ambiguity on the role that both Knowledge Management and Human Resource Development play on the sustainability and survivability of an organization individually, very little study exist between the two principles as experienced throughout the literature reviewed. Existing human resource development scholarly works either tries to distance themselves or entirely ignores knowledge management. Gourlay's study in 2010 provides a shift in perspective on the need of HRD on KM by reiterating that irrespective of the definition of knowledge, human resource management skills and knowledge are vital in managing it. For instance, while knowledge in itself may be difficult to manage, all the related technologies, structures, instruments, stocks, flows and even people are susceptible to a range of management disciplines and activities, including accountability and control. 


\section{RECOMMENDATIONS}

It is apparent that there is need for further explore of the topic and the following are recommendations;

- This paper could serve as a frame of reference for researchers, and could enable practitioners to gain better understanding of key requirements for maintaining competitive performance in this 21 st century via effective integration of $\mathrm{KM}$ and human capital initiatives, therefore a need for further research is a must do.

- Since its noted in the paper that the classical factors of production - land, labor and capital - are becoming secondary to knowledge as the primary resource for the New Economy (Charles and Jean-Marie, 1999). There is a need for firms to break through and shift to the knowledge economy recognizing knowledge as a core competence based on skills and experience.

\section{CONCLUSION}

In view of the above developments, it is this shift in paradigm that highlight the need for integration of both principles for the betterment and sustainability of an organization. Applying knowledge management practices like creating and sharing knowledge leads organizations to growth, innovation, the creation of new business models, and the creation of proper position in their own industry. It can be stated that, with creation and expansion of knowledge networks, not only organizations benefit, but it can be beneficial for the society, environment, and economy. Business plan should recognize at first that human resource management as an integral part of the business strategies. The rise of the so-called knowledge economy has had a major impact, with a considerable shift from HRM as a bureaucratic "personnel management" operation to the development of discrete HRD functions over the past few decades. A considerable number of experts in the area warn that HRD faces extinction if it does not respond to changes brought about by the shift from a traditional to a knowledge-based economy can play an important role in creating and developing the organizational capabilities required to compete in the knowledge economy and as such integration is the next evolutionary step. I conclude that when a firm is able to perform better than competitors; such a firm would be able to achieve sustainable advantage. Further I posit that, Human resource development, knowledge orientation, information system infrastructure are among the most important factors in the success of knowledge management. Therefore, in developing companies, the inclusion of these factors will contribute to the success of its competitive environment. 


\section{References:}

- Akinyemi, B. (2011). International Bulletin of Business Administration. An Assessment of Human Resource Development Climate in Rwanda Private Sector Organisation, 66.

- Anand, P. D., Centobelli, P. D., Cerchione, P. D., \& Lindahl, P. D. (2020). Special Issue "Knowledge Management for Sustainability-oriented Performance". Sustainability . Retrieved from https://www.mdpi.com/journal/sustainability/special_issues/knowledge_sustainability

- Armstrong, M. (2009). Armstrong's handbook of human resource management practice $11^{\text {th }}$ Ed. Derby, India: Replika Press Pvt. Ltd.

- Armstrong, M. (1996). A handbook of Personnel management practice. $6^{\text {th }}$ Ed. England, Britain: Clays Ltd, St Ives plc

- chalofsky, N.E., Rocco, T.S., \& Lane, M. (2014). handbook of human resources, Hoboken, New Jersey

- Gerber, P.D., Nel, P.S., \& Van Dyk, P.S. (1997). Human resource management $3^{R D}$ Ed. Western Cape, RSA. Thompson Publishing.

- Gloet, M. (2006). Knowledge Management and the links to HRM: Develoing Leadership and management capabilities to support sustainability. Management Research News, 0140-9174.

- Gourlay, S. (2010). Knowledge management and HRD. Human Resource Development International , 27-46.

- Ishak, N.B., Eze,U.C., \& Ling,L.S. (2010). intergrating knowledge management and human resource management for sustainable perfomance.journal of organizational knowledge management, 1-12.doi:10.5171/2010.322246

- Khasman, M.A. (2019). The impact of electronic human resource management strategies on organizational innovation by knowledge repository as mediating role,

- King, W.R., (2009). Knowledge management and organizational learning: annals of information system 4, DOI 10.1007/978-1-4419-0011-1_1,

- Mali, S. (2013, May 8). Importance of integrating Human Resource Management into a business's strategic planning process . Retrieved from SlideShare: https://www.slideshare.net/swapnilmali/importance-of-integrating-human-resourcemanagement-into-a-businesss-strategic-planning-process

- McGuire, D \& Garavan, T.N. (2011). Human resource development and society: Human resource development role in embedding corporate social responsibility, sustainability and ethics in organizations. doi:10.1177/1523422310394757

- Ragini, P. (2019, July). Importance of Human Resource Development. Retrieved from Economics Discussion: http://www.economicsdiscussion.net

- Unknown. (2018, November 5). The Integration Of Human Resource Management Methods. Retrieved from UKEssay: https://www.ukessays.com/essays/business/theintegration-of-human-resource-management-methods-business-essay.php

- Valmohammadi, C., Sofiyabadi, J., \& Kolahi, B. (2019). How do Knowledge Management Practices Affect Sustainable Balanced Performance? Mediating Role of Innovation Practices. Sustainability, 1-23.

- Wilson, J.P. (2010). Human Resource Development: Learning and training for individuals and organizations ( $2^{\text {nd }}$ ed.).

- Wright, P.M., Gardner,T.M., \& Moyniham. (2003). The impact of HR practices on the performance of business units. Human resources management journal, 13 (3), 21-36.

- Yoon, et al .(2017. Trends and Issues in Integrating Knowledge Management and Organizational Learning for Workplace Performance Improvement, 369 